\title{
Flank Free Oblique Supine Modified Lithotomy Position (FOSML) for Simultaneous Anterograde and Retrograde Endourological Access. Single Centre Experience
}

\author{
Sharma Vikas*, Faridi Shazib, Sharma Aditya and Yadav Rahul \\ Department of Urology, Rajiv Gandhi Super Speciality Hospital, Tahirpur, Delhi, India \\ *Corresponding Author: Sharma Vikas, Department of Urology, Rajiv Gandhi \\ Super Speciality Hospital, Tahirpur, Delhi, India.
}

DOI: $10.31080 /$ ASMS.2020.04.0577
Received: February 20, 2020

Published: February 29, 2020

(c) All rights are reserved by Sharma Vikas.,

et al.

\begin{abstract}
Objective: To determine safety and efficacy of FOSML position in achieving simultaneous antegrade nephroscopic and retrograde ureteroscopic access in simultaneous management of renal and ureteric stone disease.

Methods: From May 2018 to August 2019, 10 procedures were performed in the FOSML position requiring management of renal stones by supine approach and retrograde uretroscopic lithotripsy for ureteric stones. The indication for these procedures was the presence of renal stone with ipsilateral or contralateral ureteric stone. All procedures were performed using simultaneous anterograde nephroscopic and retrograde ureteric access with the patient under general anesthesia.

Results: All patients underwent preoperative radiological investigation in form of noncontrast CT scan KUB along with anesthesia fitness related investigations. Out of 10 patients, 6 patients underwent supine Percutanous nephrolithotomy (SPCNL) with contralateral ureteroscopic lithotripsy and 4 patients underwent SPCNL with ipsilateral ureteroscopic lithotripsy. All patients underwent DJ stent placement after lithotripy or stone fragment removal and were discharged on second postoperative day.

Conclusion: Antegrade nephroscopic with retrograde ureteroscopic access is safe and effective in FOSML position. It has shorter operative time as both ureteric and renal stones are operated simultaneously and avoids staged approached to management of ureteric and renal stones.
\end{abstract}

Keywords: Supine Percutaneous Nephrolithotomy; Retrograde Ureteroscpy; FOSML Position; Ureteric Stone

\section{Introduction}

In 1955, technique of percutaneous renal access with the patient in prone position was described [1]. After a period of 20 years, the percutaneous nephrolithotomy (PCNL) procedure was developed [2], and later on the technique of stone manipulation through PCNL was standardized [3]. PCNL in prone position is still considered as most common approach for percutaneous renal access but Management of patients with renal stones along with ureteric stones commonly requires staged approach as it is not possible to achieve ureteroscopic access during prone percutaneous nephrolithotomy (PPCNL) in conventional manner. If both procedures are done in single stage, operative time increases as one procedure is followed by other.

Supine percutaneous nephrolithotomy (SPCNL) has the advantage of simultaneous ureteroscopic and nephroscopic access. we report the feasibility of simultaneous nephroscopic and retrograde uretroscopic access in flank free oblique supine modified lithotomy (FOSML) position.

\section{Patients and Methods}

Patients with both ureteric and renal stones who would otherwise have been treated in staged or in consecutive manner, were included in the study. Informed consent was taken for surgery. All patients underwent preoperative radiological investigation in form of non-contrast CT scan KUB along with anesthesia fitness related investigations.

Patient Position: Before positioning the patient, marking of important Surface landmarks (Ribs, Iliac crest and Posterior axillary lines) were done (Figure 1). Patient is turned lateral $\left(90^{\circ}\right)$ towards contralateral side and upper back is rested against padded support. Both Lower limbs are supported and fixed on lithotomy stirrups and ipsilateral buttock rests on soft Pad. Ipsilateral lower limb is slightly extension on hip with knee partially flexed and goes down below the level of table. Contralateral lower limb is kept in conventional lithotomy position with flexion abduction, external rotation at hip and flexion at knee [4]. 


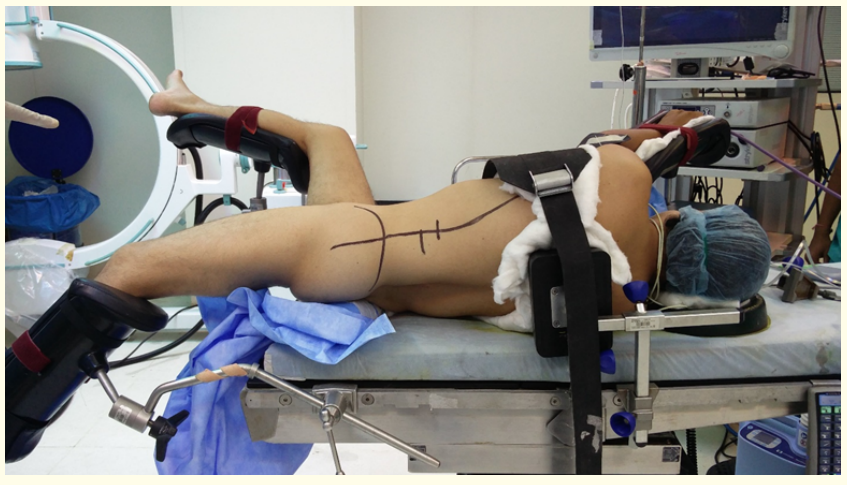

Figure 1

\section{Surgical technique}

\section{- Ipsilateral uretric stone with renal stones}

After positioning the patient, Cystoscopy was performed and attempt is made to pass guide wire is passed beyond ureteric calculus. If wire fail to pass across the stone cystoscopically, then uretroscopic approach was taken, ureteric catheter was advanced over the wire into the pelvic calyceal system and retrograde pyelography was done through ureteric catheter to delineate calyceal anatomy. Nephroscopic access is achieved by triangulation technique with under fluoroscopic guidance and tract was dilated up to 24 Fr. After achieving desired amplatz postion, ureteroscopy was performed. Both ureteroscopic and nephroscopic lithotripsy was done simultaneously (Figure 2).

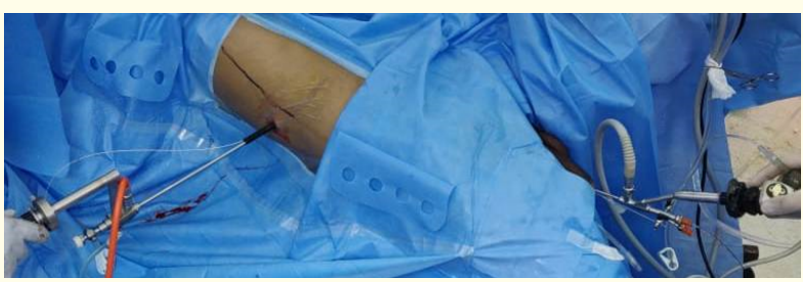

Figure 2

\section{- Contralateral ureteric stone with renal stone}

Procedure was similar to ispilateral ureteric stone with renal stone except there was no need of special focus on negotiating or manipulating guide wire across the stone for ureteric catheter placement for retrograde pyelogram (Figure 3).

Before ureteroscopy, ureteric orifice was dilated with balloon dilators and 6/7.5 Fr ureteroscope were used. Pneumatic energy was used for lithotripsy as it was the only available equipment. All patients underwent DJ stent placement after lithotripsy or stone fragment removal along with nephrostomy tube placement for 24 hours. Patients with contralateral ureterocopic lithotripsy underwent bilateral DJ stent placement.

\section{Results}

Total of 10 patients underwent both ureteroscopic and nephroscopic procedure simultaneously. Data was tabulated in 2 groups,

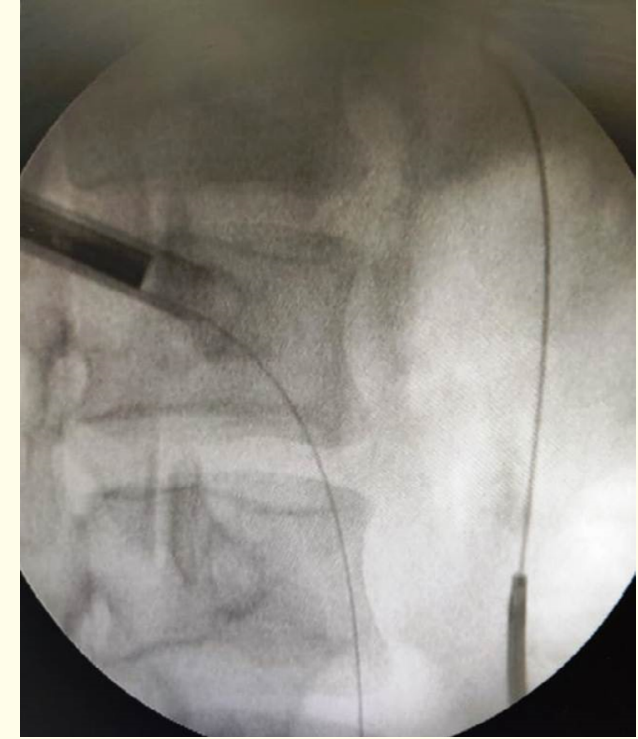

Figure 3

group A were renal stones with contralateral ureteric stones and group B were renal stones with ipsilateral ureteric stones (Table 1). Group A had 6 patients and location of ureteric stone were 3 stone mid ureteric, 2 lower ureteric and 1 upper ureteric stone.

\begin{tabular}{|l|c|c|c|}
\hline S. No & $\begin{array}{c}\text { Renal stone } \\
\text { size }\end{array}$ & Calyx punctured & $\begin{array}{c}\text { Ureteric stone } \\
\text { location }\end{array}$ \\
\hline 1 & $2 \times 1.8$ & Lower calyx & Mid ureter \\
\hline 2 & $1.9 \times .3$ & Mid calyx & Lower ureter \\
\hline 3 & $2.1 \times 1.5$ & Lower calyx & Mid ureter \\
\hline 4 & $2.9 \times 1.2$ & Lower calyx & Lower ureter \\
\hline 5 & $2.1 \times 1.3$ & Mid calyx & Upper ureter \\
\hline 6 & $2.2 \times 2.1$ & Lower calyx & Mid ureter \\
\hline
\end{tabular}

Table 1 A: Characteristics of Renal stones with contralateral ureteric stones (Group A).

\begin{tabular}{|l|c|c|c|}
\hline S.No & $\begin{array}{c}\text { Renal } \\
\text { stone size }\end{array}$ & Calyx punctured & $\begin{array}{c}\text { Ureteric stone } \\
\text { location }\end{array}$ \\
\hline 1 & $2.2 \times 1$ & Inferior calyx & Lower ureter \\
\hline 2 & $2.3 \times 1.2$ & Mid calyx & Mid ureter \\
\hline 3 & $2.9 \times 1.2$ & Inferior calyx & Lower ureter \\
\hline 4 & $1.5 \times 1$ & Inferor calyx & Lower ureter \\
\hline
\end{tabular}

Table 1 B: Characteristics of renal stones with ipsilateral ureteric stones (Group B).

\section{Table 1:}

A: Characteristics of Renal stones with contralateral ureteric stones (Group A).

B: Characteristics of renal stones with ipsilateral ureteric stones (Group B).

There were 4 patients in Group B, 3 lower ureteric and 1 mid ureteric stones were managed. All punctures were infracostal. In both the groups renal stones were managed with single renal access tract. Nephrostomy tube was removed on first post operative 
day and per urethral catheter removed on second post-operative day.

All patients had normal renal parameters preoperatively and did not require additional dj stenting procedure prior to stone management. No significant intraoperative blood loss was noticed and postoperative blood investigations did not indicate need for blood transfusion.

No patient required second look procedure and all patients were discharged on second postoperative day after meeting the discharge criteria. Patient position did not result in any operative or postoperative complications like anesthesia related thoracic pressure changes, neuropraxia, joint problem.

\section{Discussion}

Prone position is the most common approach for renal access but achieving retrograde ureteroscopic access is not possible in same position. Grasso., et al. [5] achieved simultaneous antegrade and retrograde renal access in Prone Split Leg and Flank Roll Positioning only through use of flexible instruments. Flexible instruments are more fragile and expensive compared to rigid ones. In FOSML position there is no need of dependency on flexible instruments as same was achieved with rigid instruments.

Valdivia., et al. introduced supine position for PCNL and demonstrated surgical and anesthesia related advantages [6]. Over the period other positions like Galdakao-modified Valdivia position [7] and Bart's Modified Lateral Position [8] also tried to achieve similar outcomes.

Simultaneous renal access through retrograde ureteroscopy is an advantage of SPCNL. Our aim was to demonstrate surgical advantage of FOSML position in achieving reterograde ureteroscopic and nephroscopic lithotripsy and provide option of FOSML position to surgeons. Simultaneous nature of performing two surgeries at the same time also allows bidirectional traction on guidewires, which helps in avoiding intraoperative complication like wire accidental wire dislodgement or removal and avoids additional operative time loss in managing such complications.

Disadvantage of performing simultaneous procedure was the need of additional instruments like camera head, light source, lithotripsy equipment and two operating surgeons. Need for operative table accesories like bolsters and leg supports along with fluoroscopic compatibility of operating table is must. Compared with the prone position SPCNL has been reported to save 30 - 40 minutes of surgery time when compared with PPCNL [9]. Simultaneous nature of performing ureteroscopic procedure with SPCNL as and when required further saves operative time and reduces surgical and anesthesia related morbidity.

\section{Conclusion}

Simultaneous nephroscopic and retrograde uretroscopic access in flank free oblique supine modified lithotomy (FOSML) position is safe and feasible and reduces the operative time by avoiding performing both procedures in consecutive manner. Experiences with more cases are required for detailed assessment.

\section{Bibliography}

1. Goodwin WE., et al. "Percutaneous trocar (needle) nephrostomy in hydronephrosis". Journal of the American Medical Association 157 (1955): 891-894.

2. Fernström I and Johansson B. "Percutaneous pyelolithotomy: a new extraction technique". Scandinavian Journal of Urology and Nephrology 10 (1976): 257-259.

3. Alken P., et al. "Percutaneous stone manipulation". The Journal of Urology 125 (1981): 463-466.

4. Adittya K Sharma and Rahul Yadav. "Supine PCNL in FlankFree Oblique Supine Modified Lithotomy (FOSML) Position: Our Point of Technique". Journal of Urology Nephrology 3 (2018): 000139.

5. Grasso M., et al. "Prone split leg and flank roll positioning: simultaneous antegrade and retrograde access to the upper urinary tract". Journal of Endourology 7 (1993): 307-310.

6. Valdivia-Uria JG., et al. "Why percutaneous nephroscopy is still performed with patient prone?" Journal of Endourology 4 (1990): 269-272.

7. Gaspar Ibarluzea., et al. "Supine Valdivia And Modified Lithotomy Position For Simultaneous Anterograde And Retrograde Endourological Access". BJU International 100 (2007): 233236.

8. Moraitis K., et al. "Antegrade/Retrograde Upper Urinary Tract Access: Bart's Modified Lateral Position for Complex Upper Tract Endourologic Pathologic Features". Urology (2012).

9. Rana AM., et al. "Tubeless PCNL with Patient in Supine Position: Procedure for all Seasons?-with Comprehensive Technique”. Urology 71 (2008): 581-585.

\section{Assets from publication with us}

- Prompt Acknowledgement after receiving the article

- Thorough Double blinded peer review

- Rapid Publication

- Issue of Publication Certificate

- High visibility of your Published work

Website: https://www.actascientific.com/

Submit Article: https://www.actascientific.com/submission.php Email us: editor@actascientific.com

Contact us: +919182824667 